\title{
RESPONSABILIDAD MEDIOAMBIENTAL: ¿EXIGIR GARANTÍAS FINANCIERAS EN TIEMPOS DE CRISIS? ${ }^{1}$
}

\author{
José Miguel Beltrán CAstellanos \\ Investigador FPU \\ Universidad de Alicante. Departamento de Estudios Jurídicos del Estado \\ jmiguel.beltran@ua.es
}

Recibido: 22 de febrero de 2016 / Aceptado: 12 de abril de 2016

RESUMEN: En este trabajo se analiza cómo, a través de las sucesivas reformas de la Ley de Responsabilidad Medioambiental, se ha producido la deslegalización de la exigencia de las garantías financieras, lo que ha puesto en peligro la "efectividad del régimen de responsabilidad medioambiental". De esta forma, los operadores de numerosas actividades potencialmente contaminantes están exentos de llevar a cabo el análisis de riesgos medioambientales, así como de contar con un respaldo financiero para el caso de que produzcan un daño al medio ambiente.

RESUM: Aquest treball analitza com mitjançant les successives reformes de la Llei de Responsabilitat Mediambiental s'ha produït la deslegalització de l'exigència de les garanties financeres, posant en perill “l'efectivitat del règim de responsabilitat mediambiental”. D'aquesta forma, els operadors de nombroses activitats potencialment contaminants estan exempts de dur a terme l'anàlisi de riscos mediambientals, així com, de comptar amb un suport financer per al cas de que produeixin un dany al medi ambient.

ABSTRACT: This paper analyzes how the successive reforms of the Environmental Liability Law have brought about the degalization of the requirement of financial

\footnotetext{
${ }^{1}$ El texto que se presenta fue seleccionado y defendido como comunicación en el congreso "Derecho ambiental para una economía verde", celebrado en A Coruña los días 19 y 20 de noviembre de 2015.
} 
guarantees, which has endangered the "effectiveness of the environmental liability regime." Environmental risk analysis is not mandatory for operators of many potentially polluting activities, and they also have financial support should any damage be done to the environment.

Palabras clave: Responsabilidad medioambiental — Garantías financieras - Crisis económica.

Paraules clau: Responsabilitat mediambiental - Garanties financeres - Crisi econòmica.

Keywords: Environmental liability — Financial guarantees — Economic crisis.

Sumario: I. Planteamiento de la cuestión. II. La deslegalización de la exigencia de constituir una garantía financiera. 1. Evolución normativa. 2. Consecuencias de la deslegalización. III. Conclusiones. IV. Bibliografía. V. Legislación.

\section{PLANTEAMIENTO DE LA CUESTIÓN}

En España, la reparación de los daños causados por los operadores económicos al medio ambiente se regula en la Ley 26/2007, de 23 de octubre, de Responsabilidad Medioambiental (LRM), que establece un régimen administrativo de responsabilidad ambiental de carácter objetivo (para las actividades contenidas en el anexo III) e ilimitado, basado en los principios de "prevención" y de "quien contamina paga". Se trata de una ley que trae causa de la Directiva 2004/35/CE del Parlamento Europeo y del Consejo, de 21 de abril de 2004, sobre responsabilidad medioambiental en relación con

\footnotetext{
${ }^{2}$ Este principio se haya reconocido desde el primer Programa Comunitario de Acción Ambiental (19731976) y está incorporado a los tratados desde el Acta Única Europea de 1986, introduciendo un nuevo título en el Tratado constitutivo de la CE (tít. VII arts. $130 \mathrm{R}$ a $130 \mathrm{~T}$ ). Actualmente, el principio "quien contamina paga" se encuentra plasmado en el más alto nivel posible en el Derecho comunitario (tít. XVI art. 130R. 2 TUE), siendo para la mayoría de los autores la piedra angular del Derecho ambiental. Como sostiene JORDANO FRAGA, J., La protección del derecho a un medio ambiente adecuado, Bosch, Barcelona, 1995, pp. 137-139, "significa optar entre las diversas alternativas posibles de distribución de los costes de descontaminación (sociedad en su conjunto-contaminador directo), por la solución en que los costes se imputan al contaminador directo".
} 
la prevención y reparación de daños medioambientales ${ }^{3}$ (DRM), y que garantiza que los daños al ambiente sean reparados siempre y a costa del operador que causa el daño, no siendo, por tanto, el Estado o las Comunidades Autónomas (es decir, los ciudadanos), quienes tengan que asumir los costes del siniestro.

Dicho régimen presenta las siguientes características principales ${ }^{4}:$ (1) se trata de una responsabilidad objetiva e ilimitada, de alcance no universal, pero sí aplicable a un amplio conjunto de actividades económicas o profesionales ${ }^{5}$; (2) se trata de un régimen dirigido única y exclusivamente a la reparación in natura del daño ambiental, excluyendo cualquier otra forma de reparación (indemnizaciones sustitutorias) ${ }^{6}$; (3) se trata de un régimen que confiere una amplia legitimación activa para la exigencia de responsabilidad, que incluye en todo caso a las asociaciones ecologistas ${ }^{7} ; \mathrm{y}$, finalmente, (4) se trata de una responsabilidad que se dilucida en primera instancia en sede administrativa y no en vía judicial (civil).

Asimismo, para garantizar que el operador, en el ejercicio de su actividad económica, disponga de los recursos económicos suficientes para hacer frente a los costes derivados de la adopción de las medidas de prevención, de evitación y de reparación de los daños medioambientales, la LRM establece en el artículo 24.1 la obligación, por parte de todo operador que ejerza las actividades incluidas en el anexo III, de disponer de una garantía

\footnotetext{
${ }^{3}$ DOUE L 143, de 30 de abril de 2004. Modificada parcialmente (en cuanto a la introducción de dos nuevos tipos de actividades en el anexo III) por la Directiva 2006/21/CE del Parlamento Europeo y del Consejo, de 15 de marzo de 2006, sobre la gestión de los residuos de industrias extractivas (DOUE núm. 102, de 11 de abril de 2006, páginas 15 a 33); la Directiva 2009/31/CE del Parlamento Europeo y del Consejo, de 23 de abril de 2009, relativa al almacenamiento geológico de dióxido de carbono (DOUE núm. 140, de 5 de junio de 2009, páginas 114 a 135); y por la Directiva 2013/30/UE del Parlamento Europeo y del Consejo, de 12 de junio de 2013, sobre la seguridad de las operaciones relativas al petróleo y al gas mar adentro (DOUE núm. 178, de 28 de junio de 2013, páginas 66 a 106), que modifica la definición de daños a las aguas para asegurar que la responsabilidad del operador en virtud de dicha Directiva se aplique a las aguas marinas de los Estados miembros, según se define en la Directiva 2008/56/CE [art. artículo 2, apartado 1, letras a) y b)].

${ }^{4}$ Vid. VALENCIA MARTÍN, G., "La responsabilidad medioambiental”, Revista General de Derecho Administrativo, núm. 25, 2010, pp. 1-62, pp. 15-19.

${ }^{5}$ Concretamente a las actividades consideradas como "de gran riesgo para el medio ambiente" y que se recogen en el anexo III de la Ley.

${ }^{6}$ También llamada "reparación por el equivalente", supone la restitución del bien dañado al estado en que se encontraba antes de sufrir una agresión (devolución a su estado primitivo).

${ }^{7}$ Estamos ante la misma legitimación y con los mismos requisitos que (bajo el rótulo impropio de "acción popular") la Ley 27/2006 (por la que se regulan los derechos de acceso a la información, de participación pública y de acceso a la justicia en materia de medio ambiente, pero que en esta ley viene referida únicamente a la vía de recurso administrativo o contencioso-administrativo) contempla hoy con carácter general en el campo ambiental, mientras que en materia de responsabilidad medioambiental se extiende también al procedimiento administrativo previo, incluyendo la posibilidad de su iniciación o puesta en marcha, lo que representa un plus indudable. VALENCIA MARTÍN, "La responsabilidad..." cit., p. 53.
} 
financiera obligatoria ${ }^{8}$, salvo excepciones (art. 28) ${ }^{9}$. Por tanto, ante el elevado coste de reparar los daños causados al medio ambiente, el contar con una garantía financiera ${ }^{10}$ que respalde el patrimonio del operador permite que esa reparación sea "efectiva".

A partir de aquí, las sucesivas normas que se han aprobado y que modifican la LRM han ido retrasando y excepcionando la exigencia de constituir la garantía financiera. Un primer paso en este sentido se adoptó con la Orden ARM/1783/2011, de 22 de junio, por la que se establece el orden de prioridad y el calendario para la aprobación de las órdenes ministeriales a partir de las cuales será exigible la constitución de la garantía financiera obligatoria ${ }^{11}$. Para establecer el mencionado calendario, la Orden clasifica las actividades por sectores y les asigna una prioridad usando tres criterios (el primero, actividades IPPC; el segundo, el índice de accidentabilidad; y el tercero, la existencia de obligaciones previas en materia de análisis de riesgos o relativas a la constitución de algún tipo de seguro o garantía económica por daños al medio ambiente). Así, la

\footnotetext{
${ }^{8}$ La DRM es una "directiva de mínimos", tal y como explican el considerando 29 y el artículo 16 de la propia norma comunitaria. Por ello, los Estados miembros pueden adoptar disposiciones más rigurosas en relación con la prevención y reparación de daños medioambientales. Y haciendo uso de esta posibilidad (en desarrollo de lo dispuesto en el artículo 14.1: "Los Estados miembros adoptarán medidas para fomentar el desarrollo, por parte de los operadores económicos y financieros correspondientes, de mercados e instrumentos de garantía financiera, incluyendo mecanismos financieros en caso de insolvencia, con el fin de que los operadores puedan recurrir a garantías financieras para hacer frente a sus responsabilidades en virtud de la presente Directiva"), España ha sido uno de los ocho Estados miembros de la UE que han establecido una garantía financiera obligatoria para cubrir la responsabilidad ambiental (los otros países son Bulgaria, Portugal, Grecia, Hungría, Eslovaquia, Chequia y Rumanía). Decisión que debe considerarse positiva, pues refuerza el principio de prevención y presiona a los operadores para adoptar comportamientos más prudentes y cautelosos, además de, como señala ESTEVE PARDO, J., La Ley de Responsabilidad Medioambiental. Comentario Sistemático, Marcial Pons, Madrid, 2008 , p. 13, "suponer la entrada del sector financiero y de los seguros como un nuevo e importante protagonista en el sistema de responsabilidad medioambiental".
}

${ }^{9}$ Dejando aparte el apartado d), que precisamente motiva la presente comunicación, las exenciones a la obligación de constituir la garantía afectarían, en principio, a: a) los operadores de aquellas actividades susceptibles de ocasionar daños cuya reparación se evalúe por una cantidad inferior a 300.000 euros; b) los operadores de actividades susceptibles de ocasionar daños cuya reparación se evalúe por una cantidad comprendida entre 300.000 y 2.000 .000 de euros que acrediten, mediante la presentación de certificados expedidos por organismos independientes, que están adheridos con carácter permanente y continuado, bien al sistema comunitario de gestión y auditoría medioambientales (EMAS), bien al sistema de gestión medioambiental UNE-EN ISO 14001 vigente; y c) la utilización de los productos fitosanitarios y biocidas a los que se refiere el apartado 8.c) y d) del anexo III, con fines agropecuarios y forestales, quedando, por tanto, exentos de efectuar la comunicación prevista en el artículo 24.3.

${ }^{10}$ El artículo 26 de la LRM admite tres modalidades de constitución de garantía financiera, que podrán ser alternativas o complementarias entre sí: a) una póliza de seguro; b) la obtención de un aval; o c) la constitución de una reserva técnica mediante la dotación de un fondo ad hoc con materialización en inversiones financieras respaldadas por el sector público.

11 BOE, núm. 154, de 29 de junio de 2011, páginas 69142 a 69153 (12 pp.). La aprobación, por el Ministerio de Medio Ambiente, y Medio Rural y Marino, de esta orden obedece a la previsión contenida en la disposición final cuarta de la LRM, previo acuerdo de la Comisión Delegada del Gobierno para Asuntos Económicos y previa consulta a las Comunidades Autónomas y a los sectores afectados. 
publicación de las órdenes ministeriales a partir de las cuales será exigible la constitución de la garantía financiera obligatoria de los sectores de actividad que estén clasificados con el nivel de prioridad 1 se publicarán entre los dos y tres años siguientes a la entrada en vigor de esta orden; para los sectores con nivel de prioridad 2, entre los tres y cinco años; y para los sectores con nivel de prioridad 3, entre los cinco y ocho años siguientes.

En la práctica, resulta que la gran mayoría de sectores se clasifican con un nivel de prioridad $3^{12}$, de forma que la exigencia de la garantía financiera podría retrasarse hasta los ocho años siguientes a la publicación de la Orden, es decir, hasta $2019^{13}$. Por tanto, se introduce una "barrera temporal" a la efectividad de la LRM, pues hasta pasados varios años no se exigirá una garantía financiera que asegure la reparación de los daños causados al medio ambiente por el operador, sobre todo en los casos de insolvencia o quiebra de la empresa (en la que podría incurrir, precisamente, por manifestarse un eventual daño al medio y no contar con un instrumento financiero de respaldo) ${ }^{14}$.

\footnotetext{
${ }^{12}$ Con nivel de prioridad 1 solo se clasifican las instalaciones de combustión con una potencia térmica de combustión superior a $50 \mathrm{MW}$ (IPPC 1.1) y las instalaciones para la valorización de residuos peligrosos, incluida la gestión de aceites usados, o para la eliminación de dichos residuos en lugares distintos de los vertederos, de una capacidad de más de 10 toneladas por día (IPPC 5.1). Mientras que de nivel 2 se clasifican: las coquerías (IPPC 1.3); las refinerías de petróleo y gas (IPPC 1.2); las instalaciones químicas que utilicen un procedimiento químico o biológico para la fabricación de medicamentos de base (IPPC 4.5); las instalaciones para la producción de fundición o de aceros brutos (fusión primaria o secundaria), incluidas las correspondientes instalaciones de fundición continua de una capacidad de más de 2,5 toneladas por hora (IPPC 2.2); las fundiciones de metales ferrosos con una capacidad de producción de más de 20 toneladas por día (IPPC 2.4); las instalaciones para la transformación de metales ferrosos mediante aplicación de capas de protección de metal fundido con una capacidad de tratamiento de más de 2 toneladas de acero bruto por hora (IPPC 2.3.c) y los vertederos de todo tipo de residuos que reciban más de 10 toneladas por día o que tengan una capacidad total de más de 25.000 toneladas, con exclusión de los vertederos de residuos inertes (IPPC 5.2).
}

${ }^{13}$ Según el apartado VI de la exposición de motivos del Real Decreto 183/2015 (norma a la que nos referiremos en el apartado II de este trabajo), dado que han pasado más de tres años desde la publicación de la Orden ARM/1783/2011, de 22 de junio, tras la entrada en vigor de este real decreto, se iniciará la tramitación de la orden ministerial que fije la fecha a partir de la cual será exigible la constitución de la garantía financiera obligatoria prevista en el artículo 24 de la Ley 26/2007, de 23 de octubre, para las actividades del anexo III de la Ley 26/2007, de 23 de octubre, que mantienen esta obligación, clasificadas con nivel de prioridad 1 y 2, conforme al anexo de la Orden ARM/1783/2011, de 22 de junio. Las órdenes ministeriales relativas a los sectores de actividad que estén clasificados con el nivel de prioridad 3 conforme al anexo de la Orden ARM 1783/2011, de 22 de junio, se publicarán entre los cinco y ocho años siguientes a la entrada en vigor de dicha orden, es decir, entre el 22 de junio de 2016 y el 22 de junio de 2019.

${ }^{14}$ El 7 de abril de 2015 se publicó, para su trámite de participación pública, el "Proyecto de Orden Ministerial por la que se establece la fecha a partir de la cual será exigible la constitución de la garantía financiera obligatoria para las actividades del anexo III de la Ley 26/2007, de 23 de octubre, clasificadas como nivel de prioridad 1, y nivel de prioridad 2, mediante la Orden ARM/1783/2011, de 22 de junio". Orden que, por el momento, aún no sabemos cuánto tiempo va a tardar en ser aprobada definitivamente, por lo que los plazos para la exigencia de la garantía se siguen demorando más y más (nótese que ha transcurrido casi un año desde que se llevó a cabo la participación pública). 


\section{LA DESLEGALIZACIÓN DE LA EXIGENCIA DE CONSTITUIR UNA GARANTÍA FINANCIERA}

\section{Evolución normativa}

Tan solo unos días después de la aprobación de la Orden mencionada supra, el 1 de julio se aprobaba el Real Decreto-Ley 8/2011, de 1 de julio, de medidas de apoyo a los deudores hipotecarios, de control del gasto público y cancelación de deudas con empresas y autónomos contraídas por las entidades locales, de fomento de la actividad empresarial e impulso de la rehabilitación y de simplificación administrativa ${ }^{15}$; norma que venía motivada por la crisis económica (como reconoce en su exposición de motivos ${ }^{16}$ ). Mediante esta, se establece la segunda barrera (en este caso ya no temporal, sino material) para la efectividad del régimen de responsabilidad medioambiental, al añadirse una importante excepción a la obligación de constituir la garantía financiera (art. 32.1) a través de la inclusión de un nuevo apartado d) en el artículo 28 de la LRM, con el texto siguiente:

Los operadores de las actividades que cumplan con los criterios y condiciones de exclusión que se establezcan reglamentariamente, de acuerdo con la disposición final tercera, quedarán exentos de constituir garantía financiera obligatoria, y por tanto de elevar una propuesta a la autoridad competente para la aplicación del procedimiento previsto en el artículo 24.3.

Por tanto, tras la reforma se permite introducir excepciones en la obligación de constituir garantías financieras, de acuerdo con "los criterios y condiciones de exclusión que se establezcan reglamentariamente". Tal habilitación vino a suponer una "carta blanca al Gobierno" para excluir cualquier sector de actividad del anexo III, al no establecerse ningún límite o condicionante legal ${ }^{17}$, además de ser introducida por un Real Decreto-Ley que nada tiene que ver con el medio ambiente y en un capítulo (el VI)

\footnotetext{
${ }^{15}$ BOE, núm. 161, de 7 de julio de 2011, páginas 71548 a 71586 (39pp.).

${ }^{16}$ Comienza el preámbulo de la norma así: "El desarrollo de la crisis financiera internacional y sus consecuencias en España han llevado al Gobierno, en los últimos meses, a adoptar diversas medidas para reforzar la capacidad de respuesta de la economía española, intensificar las previsiones de apoyo a quienes se encuentran en situaciones más difíciles en razón de la crisis y dar el máximo impulso posible a las iniciativas vinculadas con el desarrollo de nuevas formas de actividad económica y de generación de empleo".

17 Vid. LOZANO CUTANDA B., "Garantía financiera obligatoria en materia de responsabilidad medioambiental: novedades introducidas por el Real Decreto-Ley 8/2011”, Gómez-Acebo \& Pombo, noticias breves, 2011, agosto, pp. 1-2, p. 1.
} 
que lleva como título "Medidas de simplificación administrativa"18, lo que denota una mala técnica legislativa.

Se había producido la "deslegalización” de la exigencia de las garantías financieras, pero no sólo eso, pues aquellos operadores que por vía reglamentaria resultasen exentos de la obligación de constituir la garantía, también los estarían de llevar a cabo el procedimiento del artículo 24.3, es decir, de llevar a cabo el "el análisis de riesgos de la actividad"19.

Más tarde, la Ley 11/2014, de 3 de julio, por la que se modifica la Ley 26/2007, de 23 de octubre, de Responsabilidad Medioambiental ${ }^{20}$, en consonancia con la reforma iniciada por el Real Decreto-Ley anterior, matizó la redacción del apartado d) del artículo $28^{21}$ al disponer que quedan exentos de la obligación de constituir la garantía los "operadores de las actividades que se establezcan reglamentariamente atendiendo a su escaso potencial de generar daños medioambientales y bajo nivel de accidentalidad,

\footnotetext{
${ }^{18}$ La justificación que da el preámbulo de la Ley para proceder a modificar los preceptos de múltiples leyes ambientales (como son, además de la LRM, el texto refundido de la Ley de Aguas, aprobado por el Real Decreto Legislativo 1/2001, de 20 de julio; la Ley 37/2003, de 17 de noviembre, del Ruido; la Ley 16/2002, de 1 de julio, de Prevención y Control Integrados de la Contaminación; la Ley 34/2007, de 15 de noviembre, de Calidad del Aire y Protección de la Atmósfera; y la Ley 42/2007, de 13 de diciembre, del Patrimonio Natural y de la Biodiversidad) es propiciar que en más de un centenar de procedimientos la Administración se vea ahora sometida al régimen del silencio positivo y que desaparezcan las menciones a las licencias locales en esos textos normativos, con base a lo dispuesto en la disposición adicional octava de la Ley 2/2011, de 4 de marzo, de Economía Sostenible. Sin embargo, las modificaciones llevadas a cabo en la normativa ambiental reseñada no son de esa naturaleza. Muy especialmente en el caso de la LRM, pues, aparte de la modificación del artículo 28, se modifica también el artículo 29, de forma que, en relación con los costes cubiertos, se elimina el requisito de que el daño hubiese sido originado por contaminación. Y también se añade un nuevo párrafo al apartado 1 del artículo 30 para que, de constituirse la garantía por la cobertura máxima (veinte millones de euros), no se exima a los operadores de elevar una propuesta a la autoridad competente para la aplicación del procedimiento previsto en el artículo 24.3. Reformas estas dos últimas bien recibidas, pues potencian la reparación del daño, pero que no son cuestiones de silencio administrativo ni de licencias locales, sino auténticas modificaciones procedimentales y materiales del régimen de responsabilidad medioambiental.

${ }^{19}$ Artículo 24.3 LRM: "Los operadores deberán comunicar a la autoridad competente la constitución de la garantía financiera a la que vengan obligados de acuerdo con el apartado primero de este artículo. La fijación de la cuantía de esta garantía partirá del análisis de riesgos medioambientales de la actividad, o de las tablas de baremos, que se realizarán de acuerdo a la metodología que reglamentariamente se establezca por el Gobierno. La autoridad competente establecerá los correspondientes sistemas de control que le permitan comprobar el cumplimiento de estas obligaciones". Asimismo, el procedimiento para llevar a cabo dicho análisis se regula en los artículos 34 y 35 del Reglamento de desarrollo de la Ley.

${ }^{20}$ BOE, núm. 162, de 4 de julio de 2014, páginas 52139 a 52148 (10 pp.).

${ }^{21}$ En el apartado VI del preámbulo se establece que la presente ley regula los criterios que servirán de base para determinar, por vía reglamentaria, las actividades exentas de constituir garantía financiera obligatoria. Sin embargo, únicamente señala dos criterios: a) el escaso potencial de generar daños medioambientales y b) el bajo nivel de accidentalidad.
} 
quedando igualmente exentos de efectuar la comunicación prevista en el artículo $24.3^{\prime \prime 22}$.

Resulta paradójico que esta ley mantenga la exención para estos operadores de realizar el análisis de riesgos medioambientales, cuando el apartado IV de su preámbulo establece que "la experiencia adquirida durante los años de aplicación de la Ley 26/2007, de 23 de octubre, de Responsabilidad Medioambiental, ha puesto de manifiesto la necesidad de reforzar sus aspectos preventivos, para lo cual, se considera oportuno impulsar el uso de los análisis de riesgos medioambientales como herramienta de gestión del riesgo medioambiental ${ }^{, 23}$. Y es que el análisis de riesgos resulta fundamental, ya que mediante este se pueden identificar los escenarios de riesgo de cada instalación, lo que permite gestionar dicho riesgo para así reducir los posibles daños medioambientales que se puedan ocasionar. Además, permite a los operadores conocer si están obligados a constituir una garantía financiera y, en su caso, calcularla. E incluso, determinar los posibles riesgos de la actividad puede motivar a los operadores de actividades no sometidas a la obligación de constituir la garantía a contratarla de forma voluntaria, tal y como propugna ahora expresamente el artículo 24.1 in fine de la $\mathrm{LRM}^{24}$.

Meses después, el Real Decreto 183/2015, de 13 de marzo ${ }^{25}$, por el que se modifica el Reglamento de desarrollo parcial de la Ley 26/2007, de 23 de octubre, de Responsabilidad Medioambiental (aprobado por Real Decreto 2090/2008), lleva a cabo el desarrollo reglamentario del nuevo apartado d) del artículo 28 de la Ley. El apartado II de la exposición de motivos de esta norma señala que "la experiencia adquirida durante los primeros años de vigencia de este nuevo régimen de responsabilidad medioambiental puso de manifiesto que la exigencia de constituir garantía financiera a todos los operadores del Anexo III de la ley, sin más exenciones que las previstas en el

\footnotetext{
${ }^{22}$ Vid. LOZANO CUTANDA, B. y POVEDA GÓMEZ, P., "Ley 11/2014, de 3 de julio, de modificación de la Ley 26/2007, de Responsabilidad Medioambiental: análisis de sus novedades”, Gómez-Acebo \& Pombo, 2014, julio, p. 1.

${ }^{23}$ Precisamente, con este objetivo se introduce un nuevo artículo 17 bis, en el que se señala que las autoridades competentes adoptarán medidas para impulsar la realización voluntaria de análisis de riesgos medioambientales, entre los operadores de actividades susceptibles de ocasionar daños medioambientales, con la finalidad de lograr una adecuada gestión del riesgo medioambiental de la actividad.

24 "Para el resto de operadores (aquellos cuyas actividades no estén incluidas en el anexo III o los que estén exentos en virtud del art. 28), la constitución de la garantía financiera tendrá carácter voluntario", modificación introducida por el artículo único apartado 5 de la 11/2014, de 3 de julio.
}

${ }^{25}$ BOE, núm. 83, de 7 de abril de 2015, páginas 29407 a 29446 (40pp.). 
artículo 28, resultaba un tanto desproporcionada teniendo en cuenta que no todos los operadores incluidos en el anexo III presentan unos mismos índices de peligrosidad y de accidentalidad, y que por ello se consideró oportuno eximir de la obligación de constitución de garantía financiera a los operadores cuyas actividades presentasen bajo riesgo de producir daños medioambientales, sin que por ello quedasen comprometidos los principios de responsabilidad objetiva e ilimitada que presiden la Ley de responsabilidad medioambiental".

\section{Consecuencias de la deslegalización}

Tres consideraciones merece lo apuntado por la norma para justificar la regulación que establece respecto de las garantías financieras. En primer lugar, el proceso para determinar qué operadores de los incluidos en el anexo III presentan un índice de peligrosidad y accidentalidad menor es el "análisis de riesgos medioambientales" ${ }^{26}$. En efecto, sobre la base de dicho análisis es posible determinar cuándo una actividad que en principio es considerada como de riesgo para el medio ambiente (de ahí su inclusión en el anexo III de la Ley, que reproduce el anexo III de la DRM) por sus características de emplazamiento, proceso productivo, medidas de seguridad, niveles de producción etc., manifiesta un escaso potencial contaminante o bajo nivel de accidentalidad. Esa, junto con la función de servir de base para determinar la cuantía de la garantía financiera, es la finalidad del análisis de riesgos. Y lo que es más importante aún, de desprenderse del resultado del mencionado análisis que la actividad que ejerce el operador tiene un bajo nivel de peligrosidad y de accidentalidad, se aplicarían las exenciones previstas en los apartados a) y b) del artículo $28^{27}$, pues para eso están contempladas en la norma. O bien, si se superan los umbrales que marca el precepto anterior, cuanto más reducido sea el riesgo, menor será la prima que exija la aseguradora para darle cobertura.

En segundo lugar, al optar la norma por la opción de excluir en bloque numerosas actividades potencialmente contaminadoras de la necesidad de constituir la garantía

\footnotetext{
${ }^{26}$ Así lo reconocía expresamente el artículo 37 del Reglamento de desarrollo en su versión original, al decir: "Para determinar los supuestos de exención de la obligación de constituir garantía financiera se utilizarán cualquiera de los instrumentos de análisis de riesgos y de cálculo de la cuantía de la garantía financiera previstos en este reglamento".

${ }^{27}$ Vid. nota al pie núm. 8.
} 
financiera obligatoria, sobre la base de que puede que haya operadores que presenten un bajo riesgo o niveles reducidos de accidentalidad, evidentemente se comprometen los principios de responsabilidad objetiva e ilimitada, pues de igual forma que se excluye a los operadores de poco riesgo, al ser una exclusión, como decimos, en bloque, también se excepcionan los operadores de esos sectores que sí son potenciales contaminadores del medio y que presentan elevados niveles de accidentalidad.

En tercer lugar, si al menos la norma hubiese mantenido la obligación de efectuar la comunicación que prevé el artículo 24.3 y, por ende, la necesidad de llevar a cabo el análisis de riesgos, estos operadores a los que se les exime de la obligación de constituir la garantía estarían obligados a analizar y conocer el riesgo de su actividad con vistas, al menos, a adoptar medidas de seguridad mayores para sus instalaciones, o, incluso, para que voluntariamente optasen por constituir la garantía.

Pues bien, haciendo uso de la habilitación reglamentaria, el Real Decreto 183/2015 excluye, como hemos anticipado, numerosas actividades del anexo III de la obligación de constituir una garantía financiera. En concreto, el artículo 37 (operadores exentos de constituir la garantía financiera), en su apartado $2 .^{\circ}$ letra a), dispone:

[Q]uedarán obligados a constituir la garantía financiera, y por tanto a efectuar la comunicación a la autoridad competente prevista en el artículo 24.3 de la Ley 26/2007, de 23 octubre, y en el artículo 33 de este reglamento, los operadores de las siguientes actividades del Anexo III de la ley:

1. ${ }^{\circ}$ Las actividades e instalaciones sujetas al ámbito de aplicación del Real Decreto $840 / 2015$, de 21 de septiembre, por el que se aprueban medidas de control de los riesgos inherentes a los accidentes graves en los que intervengan sustancias peligrosas (operadores SEVESO) ${ }^{28}$.

2. ${ }^{\circ}$ Las actividades e instalaciones sujetas al ámbito de aplicación de la Ley 16/2002, de 1 de julio, de prevención y control integrados de la contaminación (Actividades IPPC).

$3 .^{\circ}$ Los operadores que cuenten con instalaciones de residuos mineros clasificadas como de categoría A de acuerdo a lo establecido en el Real Decreto 975/2009, de

\footnotetext{
${ }^{28}$ La norma contempla el Real Decreto 1254/1999, de 16 de julio (vigente hasta el 21 de octubre de 2015).
} 
12 de junio, sobre gestión de los residuos de las industrias extractivas y de protección y rehabilitación del espacio afectado por actividades mineras ${ }^{29}$.

Por el contrario, el apartado b) señala que, atendiendo a su escaso potencial de generar daños medioambientales y bajo nivel de accidentalidad, quedarán exentos de las obligaciones anteriores los operadores del resto de actividades del anexo III $^{30}$.

Por otro lado, dice el artículo 37.3.b), párrafo segundo:

[...] en el marco de la Comisión técnica de prevención y reparación de daños medioambientales, en el plazo de cinco años desde la entrada en vigor de este real decreto, se realizará un estudio que actualice la evaluación del potencial de generar daños medioambientales y el nivel de accidentalidad de todas las actividades del anexo III de la Ley 26/2007, de 23 de octubre, distintas a las enumeradas en el subapartado a) anterior. Dicha evaluación podrá dar lugar a la revisión de los operadores del resto de actividades del anexo III que, atendiendo a su escaso potencial de generar daños medioambientales y bajo nivel de accidentalidad quedan exonerados de constituir garantía financiera obligatoria, así como de efectuar la comunicación prevista en el artículo 24.3, al no estar incluidos en ninguno de los supuestos del apartado 2.a) anterior.

Por tanto, en el plazo de cinco años, el número de sectores de la actividad del anexo III exentos de la obligación de constituir la garantía financiera podría reducirse (y entiendo que así debería ser, sobre todo si mejora la situación económica que en un principio motivó la modificación del régimen de garantías), pero también ampliarse, de nuevo, por vía reglamentaria, sin más criterio que el estimarse un escaso potencial contaminante y bajo nivel de accidentalidad, y, de igual manera, quedarían eximidos de la obligación de llevar a cabo el análisis de riesgos medioambientales por no tener que presentar su resultado a la autoridad competente.

Finalmente, el apartado $3 .^{\circ}$ del artículo 37 establece lo siguiente:

\footnotetext{
${ }^{29}$ Los operadores de este sector de la actividad mantienen la obligación de constituir la garantía, pero se modifica la redacción contenida en el punto 14 del anexo III, que contempla lo siguiente: "La gestión de los residuos de las industrias extractivas, según lo dispuesto en la Directiva 2006/21/CE del Parlamento Europeo y del Consejo, de 15 de marzo de 2006, sobre la gestión de los residuos de industrias extractivas y por la que se modifica la Directiva 2004/35/CE". De este modo, la exigencia de constituir la garantía se circunscribe únicamente a los operadores que cuenten con instalaciones de residuos clasificadas como de "categoría A".

${ }^{30}$ Es decir, que de los 15 puntos que contiene el anexo III de la LRM, únicamente en el caso del primero y del decimocuarto se mantiene la obligación. En cualquier caso, la responsabilidad sigue siendo objetiva para todas las actividades del anexo.
} 
Los operadores de las actividades exentas de la garantía financiera prevista en la Ley 26/2007, de 23 de octubre, quedarán sujetos a la obligación de constituir las garantías financieras previstas en las normas sectoriales o específicas que les sean, en su caso, de aplicación.

Al menos, por esta vía se siguen exigiendo garantías financieras, pues, pese a que se ha eximido de la obligación de la garantía en la normativa básica ${ }^{31}$, varias leyes sectoriales o específicas exigen garantías al operador con las que cubrir las responsabilidades por daños, aunque con un alcance más limitado que la LRM o con otros fines (por ejemplo, garantizar la reparación no del ambiente, sino de los daños materiales causados a las personas) $)^{32}$.

\section{CONCLUSIONES}

Tras las reformas de la LRM a las que hemos hecho referencia, nos encontramos ante un sistema de responsabilidad medioambiental menos garantista y eficaz, pues, si los operadores de las actividades exentas de constituir una garantía financiera causan un daño al medio ambiente, previsiblemente no dispondrán (al menos no de forma obligatoria, pues voluntariamente pueden constituir la garantía y llevar a cabo el análisis de riesgos, como expresamente reconocen los artículos 24.1 in fine y 17.bis de la LRM) de recursos económicos suficientes para reparar el daño causado (lo que dependerá, por

\footnotetext{
${ }^{31}$ Como expresamente se reconoce en la disposición final primera de la LRM: "Esta Ley tiene el carácter de legislación básica de protección del medio ambiente"; y añade: "La sección $1^{\mathrm{a}}$ del capítulo IV, que constituye legislación básica de seguros".

32 Por ejemplo, la Ley 22/2011, de 28 de julio, de Residuos y Suelos Contaminados (BOE, núm. 181, de 29/07/2011), exige dos tipos de garantías financieras. La primera, en el artículo 17.7, para el productor u otro poseedor inicial de los residuos, al señalar que "podrá ser obligado a suscribir una garantía financiera que cubra las responsabilidades a que puedan dar lugar sus actividades atendiendo a sus características, peligrosidad y potencial de riesgo". La segunda, contemplada en el artículo 20.4.c), establece la obligación para los gestores de residuos, en concreto, la de "suscribir un seguro o constituir una garantía financiera equivalente en el caso de entidades o empresas que realicen operaciones de tratamiento de residuos peligrosos y cuando así lo exijan las normas que regulan la gestión de residuos específicos o las que regulan operaciones de gestión, para cubrir las responsabilidades que deriven de estas operaciones". Y otro ejemplo sería, como explica QUINTANA LÓPEZ, T., Concesión de minas y protección del medio ambiente, Tirant lo Blanch, Valencia, 2013, p. 203, el del Real Decreto 975/2009, de 12 de junio, sobre gestión de los residuos de las industrias extractivas y de protección y rehabilitación del espacio afectado por actividades mineras (BOE, núm. 143, de 13 de junio de 2009), que exige dos garantías (arts. 41 a 43) "al objeto de garantizar la ejecución del plan de restauración en su doble vertiente, comprensiva de los trabajos de rehabilitación del espacio afectado por las actividades de investigación y aprovechamiento de los recursos minerales, y de gestión de los residuos, incluida la rehabilitación de los terrenos destinados a ello".
} 
supuesto, de la magnitud de los daños causados, que en el caso de actividades de riesgo suelen ser muy elevados).

Por otro lado, como hemos advertido, la responsabilidad en la LRM es ilimitada porque obliga a reparar los daños al medio ambiente en su integridad. El operador responsable asume la obligación de devolver los recursos naturales al estado original en el que se encontraban antes del daño y de sufragar el total de los costes, y ello con independencia de cuál sea la cuantía económica a la que ascienda dicha reparación. Precisamente, es para asegurar que los operadores dispongan de los recursos económicos necesarios para hacer frente a los costes derivados de la adopción de las medidas de prevención, de evitación y de reparación de los daños medioambientales ${ }^{33}$, por lo que la Ley les exige que cuenten con una garantía financiera con la que cubrir la responsabilidad medioambiental en la que puedan incurrir.

Finalmente, la crisis económica en modo alguno puede justificar la completa exención para sectores de la actividad "en bloque" de buena parte de las obligaciones que establece la LRM, como son suscribir una garantía financiera y llevar a cabo el análisis de riesgos. Por tanto, no se debe comprometer la reparación efectiva de los recursos naturales bajo el pretexto de la mala situación económica. Si bien es cierto que en tiempos de crisis las exigencias para los operadores se pueden relajar o suavizar en pos de favorecer la recuperación económica del sector industrial, optando por soluciones menos drásticas como, por ejemplo, aumentar los umbrales a partir de los cuales el operador estaría exento de contratar una garantía en función del resultado del análisis de riesgos, al estimarse que pueda causar daños por valor de más de 300.000 euros [que es lo que estipula actualmente el artículo 28.a)] pero por debajo de una suma razonable.

\section{BIBLIOGRAFÍA}

ESTEVE PARDO, J., La Ley de Responsabilidad Medioambiental. Comentario Sistemático, Marcial Pons, Madrid, 2008.

JORDANO FRAGA, J., La protección del derecho a un medioambiente adecuado, Bosch, Barcelona, 1995.

\footnotetext{
${ }^{33}$ Apartado V de la exposición de motivos de la LRM.
} 
LOZANO CUTANDA B., "Garantía financiera obligatoria en materia de responsabilidad medioambiental: novedades introducidas por el Real Decreto-Ley 8/2011”, Gómez-Acebo \& Pombo, noticias breves, 2011, agosto.

LOZANO CUTANDA, B. y POVEDA GÓMEZ, P., "Ley 11/2014, de 3 de julio, de modificación de la Ley 26/2007, de Responsabilidad Medioambiental: análisis de sus novedades", Gómez-Acebo \& Pombo, 2014, julio,

QUINTANA LÓPEZ, T., Concesión de minas y protección del medio ambiente, Tirant lo Blanch, Valencia, 2013.

VALENCIA MARTÍN, G., "La responsabilidad medioambiental”, Revista General de Derecho Administrativo, núm. 25, 2010.

\section{LEGISLACIÓN}

Directiva 2004/35/CE del Parlamento Europeo y del Consejo, de 21 de abril de 2004, sobre responsabilidad medioambiental en relación con la prevención y reparación de daños medioambientales.

Ley 26/2007, de 23 de octubre, de Responsabilidad Medioambiental.

Orden ARM/1783/2011, de 22 de junio, por la que se establece el orden de prioridad y el calendario para la aprobación de las órdenes ministeriales a partir de las cuales será exigible la constitución de la garantía financiera obligatoria.

Real Decreto-Ley 8/2011, de 1 de julio, de medidas de apoyo a los deudores hipotecarios, de control del gasto público y cancelación de deudas con empresas y autónomos contraídas por las entidades locales, de fomento de la actividad empresarial e impulso de la rehabilitación y de simplificación administrativa.

Ley 11/2014, de 3 de julio, por la que se modifica la Ley 26/2007, de 23 de octubre, de Responsabilidad Medioambiental.

Real Decreto 183/2015, de 13 de marzo, por el que se modifica el Reglamento de desarrollo parcial de la Ley 26/2007, de 23 de octubre, de Responsabilidad Medioambiental. 